\title{
ANTIBACTERIAL, ANTIOXIDANT, CHEMICAL CONSTITUENTS, AND CYTOTOXICITY EVALUATION OF TERMINALIA ARJUNA (ROXB. EX DC.) WIGHT AND ARN
}

\author{
SAVITA KHATRI, NEETU PHOUGAT, MEHAK DANGI, ANIL KUMAR CHHILLAR*
}

Centre for Biotechnology, Maharshi Dayanand University, Rohtak, Haryana, India. Email: anil.chhillar@gmail.com

Received: 30 November 2016, Revised and Accepted: 21 December 2016

ABSTRACT

Objective: The objective of this study is to evaluate the in vitro antibacterial and antioxidant prospective of Terminalia arjuna (leaves). The most active extracts were examined for their chemical composition and cytotoxicity.

Methods: The antibacterial activity of five different extracts were examined against 8 bacterial strains (5 Gram-positive and 3 Gram-negative) using resazurin-based microtiter dilution assay (RMDA) and disk-diffusion assay. The antioxidant potential of five extracts was demonstrated using 1 , 1-diphenyl-2-picrylhydrazyl (DPPH) assay and superoxide radical scavenging assay. Chemical composition and cytotoxicity were assessed using gas chromatography-mass spectrometry (GC-MS) and hemolytic assay, respectively.

Results: According to RMDA, the acetone extract (AE) exhibited highest antibacterial activity. The AE showed highest activity against Salmonella enterica ser. typhi and Bacillus cereus with minimum inhibitory concentration, i.e., $195.31 \mu \mathrm{g} / \mathrm{ml}$. In DPPH assay, AE showed the highest radical scavenging activity with inhibition concentration ${ }_{50} 23.09 \mu \mathrm{g} / \mathrm{ml}$. In GC-MS analysis, the principal compound in AE was celidoniol (8.72 \%). According to the results of hemolytic assay, the AE showed non-toxic behavior upto $500 \mu \mathrm{g} / \mathrm{ml}$.

Conclusion: The present investigation represents T. arjuna as an incredible herb. The AE was found to possess promising antibacterial and antioxidant properties.

Keywords: Antibacterial, Antioxidant, Terminalia arjuna, Chemical composition, Cytotoxicity.

(C) 2017 The Authors. Published by Innovare Academic Sciences Pvt Ltd. This is an open access article under the CC BY license (http://creativecommons. org/licenses/by/4. 0/) DOI: http://dx.doi.org/10.22159/ajpcr.2017.v10i3.16408

\section{INTRODUCTION}

Despite the success of antibiotics development, researchers have experienced a rapid decline in eradication of infections during the past decades. Therefore, bacterial infections are still a major cause of high morbidity and mortality in human population worldwide [1]. Inappropriate diagnosis of any infection leads to targetless therapy and indiscriminate use of chemotherapeutic drugs which are responsible for treatment failure and appearance of multidrug-resistant (MDR) pathogens [2,3]. This imperative need for novel therapeutic agents leads to re-emergence of natural products for drug discovery. According to the World Health Organization, more than $80 \%$ of the world's population depends on herbal drugs for their basic healthcare demands [4]. According to Food and Drug Administration, 34\% of new approved medicines between 1981 and 2010 including anticancer drugs, and immunosuppressants were based on natural products or their derivatives [5]. Due to the presence of various structurally diverse phytochemicals, these herbs have been used as therapeutic drugs for infection treatment as well as raw materials, precursors or template for lead structures for drug development [6,7]. Phytoconstituents are also a safer alternative to prevent cancers [8]. Oxidative stress and cell death are widely related to the generation of reactive oxygen species (ROS) which attack on macromolecules. Various degenerative human diseases including Alzheimer's disease, diabetes mellitus, neurodegenerative disorders, Parkinson's disease, inflammation, atherosclerosis, cancer, and aging are associated with uncontrolled generation of free radicals [9]. Several medicinal plants are known for their antioxidant capacity since antiquity [10]. The genus Terminalia (Combretaceae) comprises nearly 200 species distributed around the world. Nearly, 24 species of Terminalia have been reported from various parts of India [11].

Terminalia arjuna (Roxb. ex DC.) Wight and Arn is generally known as Arjuna, Indradru, Partha, and Veeravriksha [12]. T. arjuna is about
60-80 feet in height, distributed in India, Burma, Mauritius, and Sri Lanka [11]. Leaves are relatively simple, usually crenulations, subopposite and with acute apex. Leaves have green upper face and pale brown lower surface. It has white sessile bisexual flowers within the short auxiliary spikes. Fruits of T. arjuna are drupe-like. Its bark is smooth and pinkish-gray in color [13]. The various parts such as bark, leaves, and fruits are used in traditional medicine system for various ailments. The bark powder has been found to possess various medicinal properties including cardioprotective properties, anti-ischemic, antioxidant [14], hypercholesterolemia effect [15], antimicrobial [16,17], anti-inflammatory, immunomodulatory, and antinociceptive activity [18]. It is also useful to cure obesity, hypertension, and hyperglycemia [19]. Various phytoconstituents including arjunin, arjunic acid, qudranoside VIII, terminarjunoside I and II, luteolin, baicalein, kempferol, oligomeric proanthocyanidins, pelargonidin, quercetin, $\beta$-sitosterol, hentriacontane, methyl oleaolate, and myristyl oleate are obtained from stem bark, root, and fruits of T. arjuna [11].

It is well established that stem bark of T. arjuna possessed a broad range of activity spectrum, however, true potential of its leaves formulations has to be explored. Hence, we have carried out this study with a broad range of representative bacterial strains and evaluate the in vitro antibacterial activity of T. arjuna. The in vitro antioxidant activity of T. arjuna was also evaluated. Chemical composition and cytotoxicity of extracts having antibacterial and antioxidant properties were assessed.

\section{METHODS}

\section{Plant material}

Fresh leaves of T. arjuna were collected from District Jhajjar, Haryana, India, in July 2013. The plant was identified from the Department of Botany, Maharshi Dayanand University, Rohtak, Haryana (India) with voucher no. CBT-01 and further authenticated with the help of flora of Haryana [20]. 


\section{Chemicals and reagents}

Petroleum ether, chloroform, acetone, methanol, dimethylsulfoxide (DMSO), hydrochloric acid, Dragendorff's reagent, ferric chloride, conc. sulfuric acid, Luria broth (LB), Luria agar (LA), resazurin dye, gentamicin, 1, 1-diphenyl-2-picryl hydrazyl radical (DPPH), ascorbic acid, nitro blue tetrazolium (NBT), sodium dihydrogen orthophosphate, di-sodium hydrogen orthophosphate, sodium chloride, NADH, phenazine metho-sulfate (PMS), gallic acid, and triton X-100 were purchased from Himedia Chemicals; India.

\section{Extraction procedure}

Fresh leaves were shade-dried for four successive weeks. Then, the dried plant material was fully grinded into powder (50.35 g) and extracted using Soxhlet's method of extraction successively in five different solvents (petroleum ether, chloroform, acetone, methanol, and water) on the basis of ascending order of their polarity. The extract suspensions were filtered through Whatman filter paper No. 1. Filtrates were then concentrated under reduced pressure at $40^{\circ} \mathrm{C}$ using a rotary evaporator (Buchi Rotavapor R-210) to yield the residues of petroleum ether soluble extract $(12.073 \mathrm{~g}, 23.98 \% \mathrm{w} / \mathrm{w})$ chloroform soluble extract $(8.226 \mathrm{~g}, 16.34 \% \mathrm{w} / \mathrm{w})$, acetone soluble extract $(6.163 \mathrm{~g}$, $12.24 \% \mathrm{w} / \mathrm{w})$, methanol soluble extract $(2.547 \mathrm{~g}, 5.06 \% \mathrm{w} / \mathrm{w})$, and water soluble extract $(1.355 \mathrm{~g}, 2.69 \% \mathrm{w} / \mathrm{w})$. Stocks solutions of concentration $25 \mathrm{mg} / \mathrm{ml}$ in DMSO (10\% v/v) were prepared [21].

\section{Bacterial strains}

Eight bacterial strains including Bacillus cereus (MTCC-10085), Staphylococcus aureus (MTCC-3160), Escherichia coli (MTCC-433), Salmonella enterica ser. typhi (MTCC-733), Bacillus subtilis (MTCC-8142), Bacillus pumilus (MTCC-2299), Serratia marcescens (MTCC-9527), and Micrococcus luteus (MTCC-8132) were obtained from Institute of Microbial Technology (IMTECH), Chandigarh.

\section{Preparation of bacterial culture}

Under sterile conditions, a single colony of the bacteria was transferred into $100 \mathrm{ml} \mathrm{LB}$ and incubated at $37^{\circ} \mathrm{C}$ for $12-18 \mathrm{hrs}$ at $120 \mathrm{rpm}$. After incubation, the culture was centrifuged at $4000 \mathrm{rpm}$ for 5 minutes. The supernatant was discarded, and the pellet was resuspended into $20 \mathrm{ml}$ phosphate-buffered saline (PBS) and centrifuged again at $4000 \mathrm{rpm}$ for 5 minutes. This step was repeated until the supernatant was clear. The pellet was then suspended in PBS. Absorbance was estimated by UV-Vis Spectrophotometer (Shimadzu) at $600 \mathrm{~nm}$, and further dilutions were made until the absorbance was recorded in the range of $0.5-1.0$, which corresponds to bacterial concentration of $5 \times 10^{6} \mathrm{CFU} / \mathrm{ml}$. This final concentration of $5 \times 10^{6} \mathrm{CFU} / \mathrm{ml}$ of log phase culture of bacteria was used for antibacterial assays [21].

\section{Disc diffusion assay}

This assay was performed in radiation sterilized Petri plates of $90.0 \mathrm{~mm}$ diameter (Tarsons). The LB agar plates were prepared and plated with bacterial culture $\left(5 \times 10^{6} \mathrm{CFU} / \mathrm{ml}\right)$. The agar petri plates were placed to dry and then the sterilized discs $(6.0 \mathrm{~mm}$ in diameter $)$ of Whatman filter paper No. 1 were placed on the surface of the agar plates. Various extracts were impregnated on the discs at a concentration of $1000 \mu \mathrm{g} /$ disc. The agar plates were incubated at $37^{\circ} \mathrm{C}$ for $24 \mathrm{hrs}$. After incubation, the zone of inhibition, if any, around the discs, was recorded. The concentration which gives the zone of inhibition of at least $7.00 \mathrm{~mm}$ diameter was considered as minimum inhibitory concentration (MIC) [21]. Otherwise no growth inhibition was recorded. Percent inhibition (\% I) for each extract was calculated [22]. Gentamicin was used as standard.

Percent inhibition $=($ Zone of inhibition of extract $/$ zone of inhibition of antibiotic) $\times 100$.

\section{Resazurin-based microtiter dilution assay (RMDA)}

RMDA was performed using 96-well plates (Tarsons) under sterile environment. Different concentrations of test extracts ranging from 12500.0 to $6.10 \mu \mathrm{g} / \mathrm{ml}$ were prepared in $100 \mu \mathrm{l}$ of LB broth by successive dilution method in 96 -well plates. Then, $10 \mu \mathrm{l}$ of resazurin indicator solution $(\times 5)$ and $10 \mu \mathrm{l}$ of bacterial suspension was added $\left(5 \times 10^{6} \mathrm{CFU} / \mathrm{ml}\right)$ to each well consecutively. Each plate had growth control as well as sterility control. The plates were prepared in triplicate and incubated at $37^{\circ} \mathrm{C}$ for $18-24 \mathrm{hrs}$ at $100 \mathrm{rpm}$. After incubation, the color change was recorded. The change of blue to pink was recorded as positive results. Resazurin (7-hydroxy-3H-phenoxazin-3-one 10-oxide), which is blue irreversibly reduced to the pink compound by viable bacterial cells. The MIC value is the lowest concentration at which the dye color remained unchanged. Each experiment was conducted in triplicates, and the average was recorded as the MIC value of the test extract against bacterial strain [21]. Gentamicin was used as standard.

\section{Total activity (TA)}

TA $(\mathrm{ml} / \mathrm{g})$ is the volume of the extract which can be diluted having the capability to restrain the bacterial growth [23]. TA = Amount extracted from $1 \mathrm{~g}$ plant material (mg/g dry weight)/MIC of the extract $(\mathrm{mg} / \mathrm{ml})$.

\section{Phytochemical tests}

The phytochemical analysis of five extracts was performed by various classical methods [24].

\section{DPPH radical scavenging activity}

Extract stocks were prepared at $1 \mathrm{mg} / \mathrm{ml}$ concentration by dissolving dry extract in methanol. A volume of $2.0 \mathrm{ml}$ of $0.004 \%$ DPPH solution in methanol was mixed with $1.0 \mathrm{ml}$ of plant extracts in methanol at various concentrations ranging from 1000.0 to $31.25 \mu \mathrm{g} / \mathrm{ml}$ and incubated at $25^{\circ} \mathrm{C}$ for $30 \mathrm{~min}$. Absorbance was taken at $517 \mathrm{~nm}$ using the UV-VIS spectrophotometer (Shimadzu). DPPH solution was reduced from purple to a product, diphenylpicryl hydrazine by radical scavenging activity of extract [21]. All experiments were performed in triplicate along with ascorbic acid (standard).

Percent inhibition was calculated using the following expression,

$\%$ inhibition $=(1-\mathrm{As} / \mathrm{Ab}) \times 100$

Where $\mathrm{Ab}$ and As stand for absorption of the blank sample and tested extract solution, respectively.

\section{Superoxide radical scavenging activity}

NBT reduction method was used to determine superoxide scavenging activity. The reaction mixture was prepared by mixing $1.0 \mathrm{ml}$ of NBT solution (312.0 $\mu \mathrm{M}$ NBT in $100.0 \mathrm{mM}$ phosphate buffer, $\mathrm{pH} 7.4$ ), $1.0 \mathrm{ml}$ NADH solution ( $936.0 \mu \mathrm{M}$ NADH in $100.0 \mathrm{mM}$ phosphate buffer, $\mathrm{pH} 7.4$ ), and $0.1 \mathrm{ml}$ different extracts of T. arjuna at different concentrations ranging from 1000.0 to $31.25 \mu \mathrm{g} / \mathrm{ml}$. Further, $100.0 \mu \mathrm{l}$ of phenazine methosulfate solution $(120.0 \mu \mathrm{M}$ PMS in $100.0 \mathrm{mM}$ phosphate buffer, $\mathrm{pH}$ 7.4) was added to the reaction mixture. Then, test tubes were incubated for $15 \mathrm{~min}$, and the absorbance was recorded at $560 \mathrm{~nm}$ using a UV-VIS spectrophotometer [21]. All experiments were performed in triplicate along with gallic acid as standard. The percent inhibition of superoxide radicals was calculated by following formula:

$\%$ inhibition $=(1-\mathrm{As} / \mathrm{Ab}) \times 100$

Where $\mathrm{Ab}$ and As stand for absorption of the blank sample and tested extract solution, respectively.

\section{Calculation of inhibition concentration $\left(\mathrm{IC}_{50}\right)$ values}

$\mathrm{IC}_{50}$ value is the amount of an antioxidant needed to decrease the initial concentration of the free radical activity by $50 \%$. A graph was plotted between $\%$ inhibition and the log 10 concentrations of the extracts.

\section{Gas chromatography/mass spectrometry (GC/MS) analysis}

The extracts were dissolved in respective solvents and filtered through $0.22 \mu \mathrm{m}$ syringe filter devices (Millipore). These extracts were analyzed for their chemical composition using a Shimadzu QP-2010 plus with thermal desorption system TD-20 GC equipped with an Turbo molecular 
pump (58.0 L/seconds for He), Rotary pump $30.0 \mathrm{~L} /$ minutes $(60 \mathrm{~Hz})$, and Column (Inert Cap Pure-WAX) flow up to $4.0 \mathrm{ml} / \mathrm{min}$ which was operated in EI mode (1.0 pg octafluoronaphthalene m/z $272 \mathrm{~S} / \mathrm{N}>200$ ). Helium was used as the carrier gas with the flow rate of $1 \mathrm{ml} /$ minutes. The injector and detector temperatures were adjusted at $250^{\circ} \mathrm{C}$ and $280^{\circ} \mathrm{C}$, respectively. Identification of chemical constituents of the extract was achieved by comparison of their retention indices with their mass spectral fragmentation patterns (NIST database/chemstation data system) [21].

\section{Cytotoxicity}

The cytotoxicity study of T. arjuna extracts was carried out by hemolytic assay. Healthy human erythrocytes were collected from volunteer and were washed thrice with PBS by centrifugation at $1500 \mathrm{rpm}$ for 10 minutes. A $2 \%(\mathrm{v} / \mathrm{v}$ ) erythrocyte suspension was treated with different concentrations of test extracts $(2000.0-62.5 \mu \mathrm{g} / \mathrm{ml})$ and incubated for $1 \mathrm{hrs}$ at $37^{\circ} \mathrm{C}$. After incubation, centrifugation was carried out at $5000 \mathrm{rpm}$ for 10 minutes. The supernatant was collected, and absorbance was recorded at $415 \mathrm{~nm}$ using an Elisa plate reader (BIORAD). PBS and triton X-100 were used as negative and positive controls, respectively. Percent hemolysis for each sample was determined, and $10 \%$ hemolysis was considered as toxic [21].

Percent hemolysis $=100-(\mathrm{OD}$ of test extract $/ \mathrm{OD}$ of positive control) $\times 100$

\section{RESULTS}

\section{Phytochemical tests}

Various chemical tests with five different extracts of T. arjuna (leaves) exhibited the presence of alkaloids, tannins, steroids, glycosides, saponins, flavonoids, and terpenoids (Table 1).

\section{Antibacterial activity}

The antibacterial potential of T. arjuna (leaves) extracts was evaluated against eight bacterial strains. According to RMDA, acetone extract (AE) was the most active extract than petroleum ether extract, chloroform extract, methanol extract (ME), and water extract (WE). The AE showed highest activity against S. enterica and B. cereus with MIC i.e., $195.31 \mu \mathrm{g} / \mathrm{ml}$. The AE showed significant TA values, which indicates the prospective to restrain the development of the test microorganisms. Maximum TA value was calculated in AE against S. enterica and B. cereus i.e., $627.69 \mathrm{ml} / \mathrm{g}$. In disk diffusion assay, the AE displayed the highest antibacterial activity against B. cereus (78.38\%), S. enterica $(73.43 \%)$, and E. coli (69.05\%). Various MIC values of different extracts against bacterial strains are shown in Table 2 along with their total activity, zone of inhibition, and percent inhibition. MIC values and zone of inhibition $(\mathrm{mm})$ of gentamicin (standard antibiotic) are also given in Table 2.

\section{Antioxidant activity}

The extracts of T. arjuna leaves exhibited a concentration dependent scavenging of DPPH radicals and superoxide radicals, which were comparable to the standards (ascorbic acid and gallic acid) at the same concentrations. A concentration-inhibition graph was plotted for each extract along with standards (Fig. 1 and 2). According to current

Table 1: Various phytochemicals present in different extracts of T. arjuna (leaves)

\begin{tabular}{llllllllll}
\hline S.N & Extract & \multicolumn{7}{c}{ Phytochemicals } \\
\cline { 3 - 8 } & & A & T & S & G & SA & F & TE \\
\hline 1 & PEE & - & + & + & - & + & - & + \\
2 & CE & + & - & + & - & + & + & - \\
3 & AE & - & + & - & + & - & + & + \\
4 & ME & + & + & + & - & - & + & - \\
5 & WE & - & - & + & - & + & - & + \\
\hline
\end{tabular}

A: Alkaloids, T: Tannins, S: Steroids, G: Glycosides, SA: Saponins, F: Flavonoids, TE: Terpenoids. Indicates absence and+indicates presence of phytochemicals, WE: Water extract, T. arjuna: Terminalia arjuna investigation, the $\mathrm{AE}$ showed highest radical scavenging activity in reference with ascorbic acid (standard) with $\mathrm{IC}_{50}$ values, i.e., $23.09 \mu \mathrm{g} / \mathrm{ml}$ and $10.95 \mu \mathrm{g} / \mathrm{ml}$, respectively, in DPPH assay. In the superoxide radical scavenging assay, AE exhibited the highest scavenging activity in reference with gallic acid (standard) with $\mathrm{IC}_{50}$ values i.e., $170.87 \mu \mathrm{g} / \mathrm{ml}$ and $24.26 \mu \mathrm{g} / \mathrm{ml}$, respectively.

\section{GCMS analysis}

The GCMS analysis revealed the chemical composition of most active extract, i.e., AE. The identified compounds along with their retention indices, \% composition, molecular weight, molecular formula, chemical nature, and chemical structures are given in Table 3. The dominant compound in AE was celidoniol ( $8.72 \%$ ). The AE was characterized by the presence of other compounds including 2,6,10-trimethyl,14-ethylene14-pentadecane $(3.04 \%)$, heneicosane $(3.02 \%)$, eicosane $(3.82 \%)$, dotriacontane $(4.50 \%)$, tetratriacontane $(6.07 \%)$, pentacosane (5.58\%), hexacosane (4.15\%), stigmast-5-en-3-ol (5.58\%), and oxirane (5.04\%).

\section{Cytotoxicity}

The cytotoxicity analysis of AE was carried out by hemolytic assay. The AE was found to be non-toxic up to $500.0 \mu \mathrm{g} / \mathrm{ml}$. However, gentamicin and ascorbic acid showed non toxic behavior toward human erythrocytes even at higher concentrations, whereas gallic acid showed moderate toxicity (Fig. 3).

\section{DISCUSSION}

The present investigation was carried out to evaluate the five different extracts of T. arjuna leaves for their antibacterial activity, antioxidant potential, and chemical composition along with their cytotoxicity. The detailed analysis of the literature showed the presence of various previous studies mostly on the pharmacological properties of stem bark and fruits of T. arjuna [11,25]. Moreover, only few studies on free radical scavenging and antibacterial activity of leaves of T. arjuna has

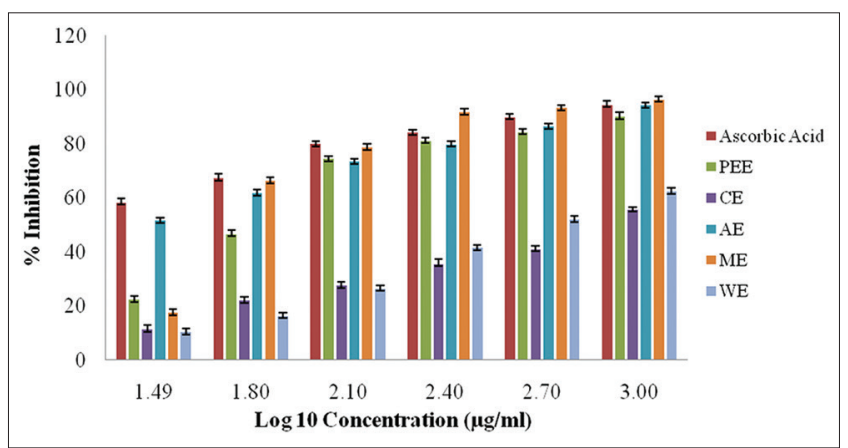

Fig. 1: 1-diphenyl-2-picrylhydrazyl radical scavenging activity of Terminalia arjuna extracts and ascorbic acid. Data expressed as means \pm standard deviation (standard deviation; $n=3$ )

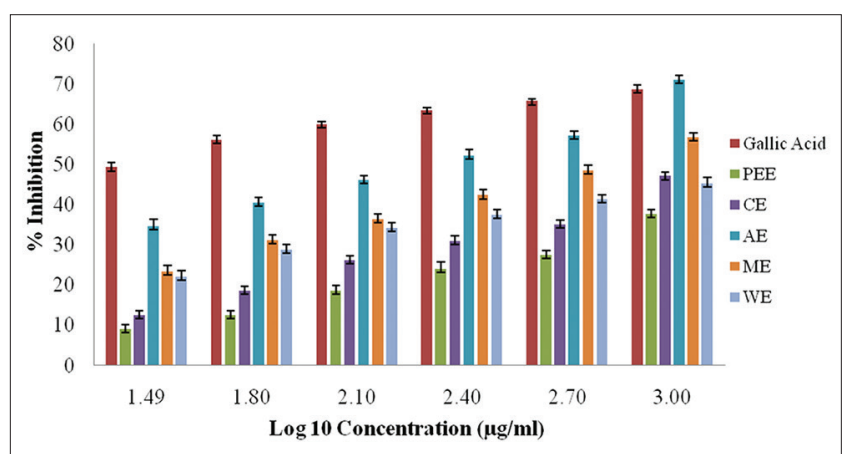

Fig. 2: Superoxide radical scavenging activity of Terminalia arjuna extracts and gallic acid. Data expressed as means \pm standard deviation $(n=3)$ 
Table 2: Antibacterial potential of T. arjuna extracts

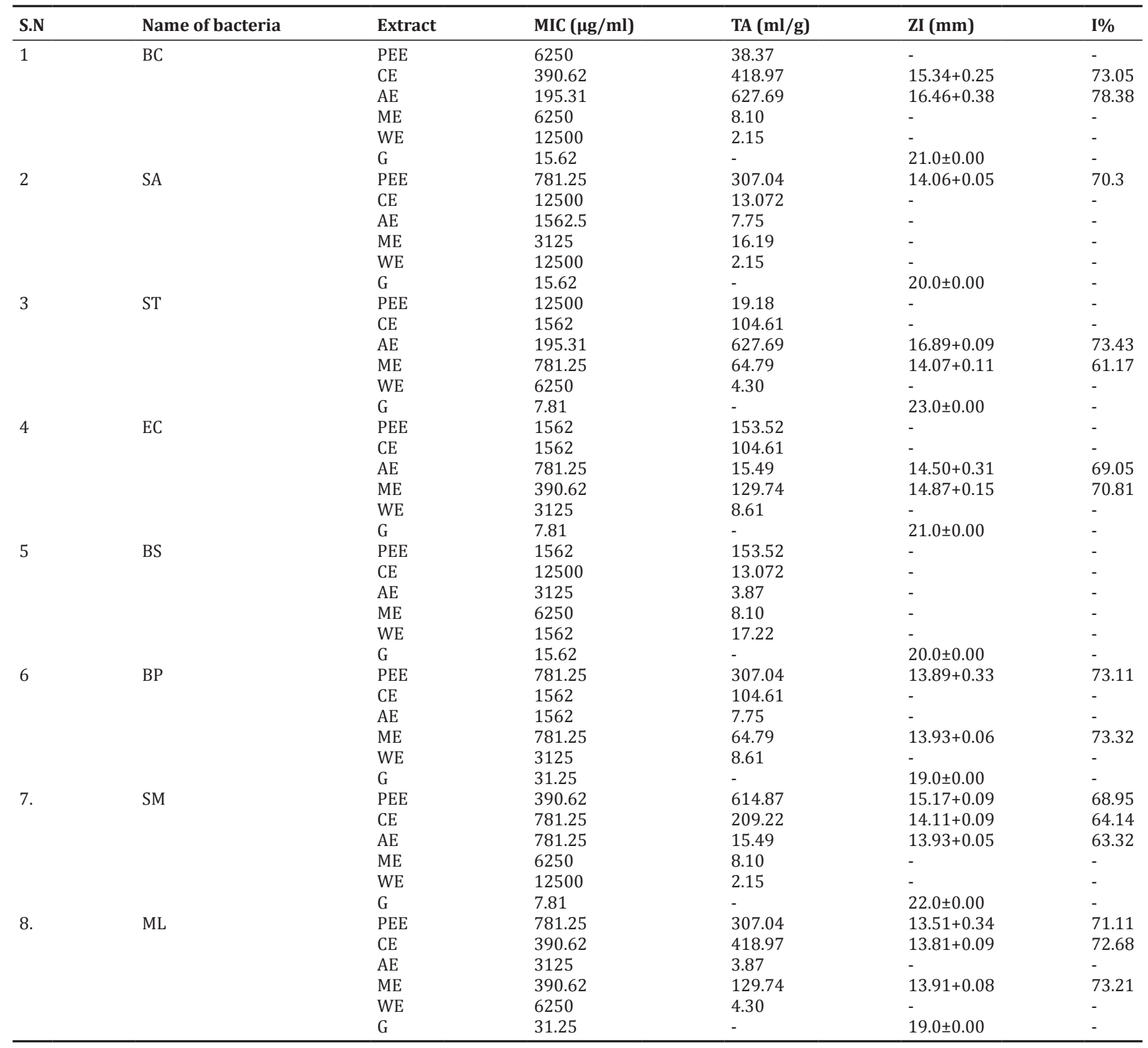

ZI: Zone of Inhibition, data expressed as means \pm SD (standard deviation; $\mathrm{n}=3$ ). BC: Bacillus cereus, SA: Staphylococcus aureus, ST: Salmonella enterica ser. typhi,

EC: Escherichia coli, BS: Bacillus subtilis, BP: Bacillus pumilus, SM: Serratia marcescens, ML: Micrococcus luteus, G: Gentamicin, AE: Acetone extract, WE: Water extract

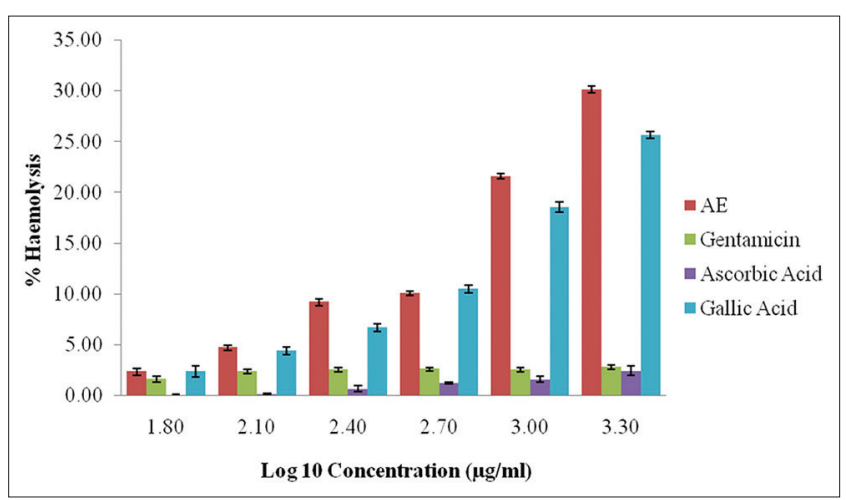

Fig. 3: Cytotoxicity of acetone extract of Terminalia arjuna along with gentamicin, ascorbic acid and gallic acid. Data are expressed as means \pm standard deviation $(n=3)$ been carried formerly. The ariel parts of T. arjuna were tested against S. aureus, Acinetobacter sp., Proteus mirabilis, E. coli, and Pseudomonas aeruginosa. The $\mathrm{AE}$ was found to be most active against $S$. aureus with MIC value, i.e., $3.12 \mathrm{mg} / \mathrm{ml}$ [17]. A few another studies were also carried out against P. aeruginosa, S. aureus, E. coli, B. cereus, B. subtilis, Lactobacillus bulgaricus, M. glutamicus, M. luteus, S. pyogenes and Streptococcus faecalis but no significant activity was observed [26,27]. In addition, we have found no such reports which evaluate antibacterial potential of AE toward S. enterica, B. pumilus, and S. marcescens In the present study, the AE exhibited highest activity against Gram-negative bacteria (S. enterica) and Gram-positive bacteria (B. cereus) with MIC, i.e., $195.31 \mu \mathrm{g} / \mathrm{ml}$. The exploration of antibacterial potential against both Gram-negative and Gram-positive bacteria displayed a broad spectrum antibacterial activity. Furthermore, information regarding the antioxidant potential of T. arjuna was also restricted to stem bark mostly. Only a few studies were carried out with leaves. Arya et al. (2012) evaluated the in vitro antioxidant potential of T. arjuna by DPPH, oxygen 
Table 3: Phytoconstituents in AE of T. arjuna (leaves) in GCMS analysis

\begin{tabular}{|c|c|c|c|c|c|c|}
\hline S.N & R time & Compound & $\%$ Area & $\begin{array}{l}\text { Molecular } \\
\text { formula (Mol. wt.) }\end{array}$ & $\begin{array}{l}\text { Nature of } \\
\text { compound }\end{array}$ & Chemical structure \\
\hline 1 & 13.069 & 2, 6, 10-trimethyl, 14-ethylene-14-pentadecane & 3.04 & $\begin{array}{l}\mathrm{C}_{20} \mathrm{H}_{38} \\
(278)\end{array}$ & Olefins & \\
\hline 2 & 19.551 & Heneicosane & 3.02 & $\begin{array}{l}\mathrm{C}_{21} \mathrm{H}_{44} \\
(296)\end{array}$ & N-Alkanes & $M$ \\
\hline 3 & 20.842 & Eicosane & 3.82 & $\begin{array}{l}\mathrm{C}_{20} \mathrm{H}_{42} \\
(282)\end{array}$ & N-Alkanes & \\
\hline 4 & 21.867 & Dotriacontane & 4.50 & $\begin{array}{l}\mathrm{C}_{32} \mathrm{H}_{66} \\
(450)\end{array}$ & N-Alkanes & WWWWWW \\
\hline 5 & 23.896 & Tetratriacontane & 6.07 & $\begin{array}{l}\mathrm{C}_{34} \mathrm{H}_{70} \\
(478)\end{array}$ & N-Alkanes & WWM \\
\hline 6 & 25.136 & Pentacosane & 5.58 & $\begin{array}{l}\mathrm{C}_{25} \mathrm{H}_{52} \\
(352)\end{array}$ & N-Alkanes & $M M W$ \\
\hline 7 & 26.663 & Celidoniol & 8.72 & $\begin{array}{l}\mathrm{C}_{29} \mathrm{H}_{60} \\
(408)\end{array}$ & N-Alkanes & WWMWMWW \\
\hline 8 & 30.597 & Hexacosane & 4.15 & $\begin{array}{l}\mathrm{C}_{26} \mathrm{H}_{54} \\
(366)\end{array}$ & N-Alkanes & MWMW \\
\hline 9 & 31.703 & Stigmast-5-en-3-ol & 5.58 & $\begin{array}{l}\mathrm{C}_{29} \mathrm{H}_{50} \mathrm{O} \\
(414)\end{array}$ & Steroid compound & \\
\hline 10 & 34.917 & Oxirane & 5.04 & $\begin{array}{l}\text { C18H360 } \\
(268)\end{array}$ & Cyclic ether & \\
\hline
\end{tabular}

AE: Acetone extract, T. arjuna: Terminalia arjuna

radical absorption capacity (ORAC), and FRAP assays and revealed that methanolic extract of T. arjuna displayed antioxidant activity at a very low concentration $(21.8 \mu \mathrm{g} / \mathrm{ml})$ in DPPH radical scavenging test. In oxygen radical absorption capacity (ORAC) assay, ME possessed antioxidant capacity with $\mathrm{IC}_{50}$ value of $42.31 \mu \mathrm{M} \mathrm{TE} / \mathrm{ml}$. However, in FRAP assay, the ME of T. arjuna showed significant ferric reducing antioxidant ability with $\mathrm{EC}_{1}$ value of $232 \mu \mathrm{g} / \mathrm{ml}$ [28]. According to another study, antioxidant activity of ME and ethyl acetate extract of $T$. arjuna leaves were carried out by using DPPH assay and ferric reducing antioxidant assay. In DPPH assay, ME and ethyl acetate extract were showed significant antioxidant potential with IC50 value of $32.16 \mu \mathrm{g} / \mathrm{ml}$ and $35.33 \mu \mathrm{g} / \mathrm{ml}$, respectively [29]. In the current investigation, DPPH assay showed the highest radical scavenging activity in $\mathrm{AE}$ with $\mathrm{IC}_{50}$ values i.e., $23.09 \mu \mathrm{g} / \mathrm{ml}$. On the other hand, in the superoxide radical scavenging assay, AE exhibited the highest scavenging activity with $\mathrm{IC}_{50}$ value of $170.87 \mu \mathrm{g} / \mathrm{ml}$. Various chemical constituents have been reported in the stem bark, roots, and fruits of T. arjuna including arjunin, arjunic acid, arjungenin, terminic acid, terminoltin, arjunolic acid, qudranoside VIII, kajiichigoside F1, arjunetin, arjunaphthanoloside, arjunglucoside IV and $\mathrm{V}$, arjunasides A-E, luteolin, gallic acid, kempferol, pelargonidin, 3-O-methyl-ellagic acid, 4-O-b-D-xylopyranoside, pyrocatechols, castalagin, casuariin, casuarinin, punicalagin, terchebulin, $\beta$-sitosterol, arjunoside I-IV, oleanolic acid, arjunetosie, arachidic stearate, cerasidin, ellagic acid, fridelin, hentriacontane, methyl oleaolate, myristyl oleate and many more. However, only a few compounds were isolated from leaves of T. arjuna including luteolin and 14,16-dianhydrogitoxigenin 3-b-D-xylopyranosyl-(1>2)-0-b-D-galactopyranoside [11]. In the present work, about 84 constituents were identified in AE of T. arjuna leaves in GC-MS analysis. Out of these, the principal compound in $\mathrm{AE}$ was celidoniol (8.72\%). Therefore, the antibacterial and antioxidant activity of $T$. arjuna extracts may be due to this component. Other minor constituents may also possess antibacterial potential. An extract is a composite mixture of several compounds, whose bioactivity can be the result of their synergistic effect. Various cytotoxicity studies of T. arjuna were only carried out with stem bark extracts. The present study demonstrated the cytotoxicity of T. arjuna leaves extracts by hemolytic assay. In hemolytic assay, AE exhibited non-toxic behavior up to $500.0 \mu \mathrm{g} / \mathrm{ml}$, respectively.

\section{CONCLUSION}

The present investigation concluded that the antibacterial and antioxidant activities of T. arjuna are not only confined to the stem bark, fruits, and roots. The study suggested that the AE of T. arjuna (leaves) possess good antibacterial and antioxidant activity and are the most valuable supplements for the ailments associated with bacterial infections and oxidative damages, respectively. The chemical analysis of leaves extract in acetone highlighted the presence of numerous phytoconstituents. The broad range antibacterial potential of AE may be due to the presence of multiple constituents or their synergistic effects. The in vitro cytotoxicity analysis indicated their non-toxic behavior toward human erythrocytes. In addition, purification and structure elucidation of the active components from the extracts will offer a better understanding of their mechanism of action and serves as a probable source of lead compounds.

\section{ACKNOWLEDGMENT}

The authors wish to thank University Grant Commission, Special Assistance Programme (SAP), Department of Biotechnology-Builder Programme, New Delhi, and Maharshi Dayanand University, Rohtak, India, for the necessary support.

\section{REFERENCES}

1. Khatri S, Kumar M, Phougat N, Chaudhary R, Chhillar AK. Perspectives on phytochemicals as antibacterial agents: An outstanding contribution to modern therapeutics. Mini Rev Med Chem 2016;16(4):290-308.

2. Kumar KT, Panda DS, Nanda UN, Khuntia S. Evaluation of antibacterial, antifungal and anthelmintic activity of Morinda citrifolia L (Noni). Int J PharmTech Res 2010;2(2):1030-2.

3. Tiwari R, Chakraborty S, Dhama K. Miracle of herbs in antibiotic resistant wounds and skin infections: Treasure of nature-A review/ perspective. Pharm Sci Monit 2013;4(4):214-48.

4. Pizzorno JE, Murray MT. Textbook of Natural Medicine. New York: Elsevier Health Sciences; 2012.

5. Butler MS, Blaskovich MA, Cooper MA. Antibiotics in the clinical pipeline in 2013. J Antibiot (Tokyo) 2013;66(10):571-91.

6. Kumar S, Pandey AK. Phenolic content, reducing power and membrane protective activities of Solanum xanihocatpum root extracts. Vegetos 
Int J Plant Res 2013;26(1):301-7.

7. González-Lamothe R, Mitchell G, Gattuso M, Diarra MS, Malouin F, Bouarab K. Plant antimicrobial agents and their effects on plant and human pathogens. Int J Mol Sci 2009;10(8):3400-19.

8. Yarney J, Donkor A, Opoku SY, Yarney L, Agyeman-Duah I, Abakah AC, et al. Characteristics of users and implications for the use of complementary and alternative medicine in Ghanaian cancer patients undergoing radiotherapy and chemotherapy: A cross-sectional study. BMC Complement Altern Med 2013;13(16):16.

9. Gülçin I. Comparison of in vitro antioxidant and antiradical activities of L-tyrosine and L-Dopa. Amino Acids 2007;32(3):431-8.

10. Strobel G, Ford E, Worapong J, Harper JK, Arif AM, Grant DM, et al. Isopestacin, an isobenzofuranone from Pestalotiopsis microspora, possessing antifungal and antioxidant activities. Phytochemistry 2002;60(2):179-83.

11. Amalraj A, Gopi S. Medicinal properties of Terminalia arjuna (Roxb.) Wight \& Arn: A review. J Tradit Complement Med 2016;6(1):1-14.

12. Sharma PC, Yelne MB, Dennis TJ. Data Base on Medicinal Plants Used in Ayurveda. New Delhi: CCRAS (The Central Council for Research in Ayurvedic Sciences); 2005.

13. Ali M. Text Book of Pharmacognosy. New Delhi, India: CBS Publishers; 1994

14. Shahriar M, Akhter S, Hossain MI, Haque MA, Bhuiyan MA. Evaluation of in vitro antioxidant activity of bark extracts of Terminalia arjuna. J Med Plants Res 2012;6(39):5286-98.

15. Patil RH, Prakash K, Maheshwari VL. Hypolipidemic effect of Terminalia arjuna (L.) In experimentally induced hypercholesteremia rats. Acta Biol Szeged 2011;55(2):289-93.

16. Nema R, Jain P, Khare S, Pradhan A, Gupta A, Singh D. Antibacterial and antifungal activity of Terminalia arjuna leaves extract with special reference to flavonoids. Basic Res J Med Clin Sci 2012;1(5):63-5

17. Aneja KR, Sharma C, Joshi R. Antimicrobial activity of Terminalia arjuna Wight \& Arn: An ethnomedicinal plant against pathogens causing ear infection. Braz J Otorhinolaryngol 2012;78(1):68-74.

18. Halder S, Bharal N, Mediratta PK, Kaur I, Sharma KK. Antiinflammatory, immunomodulatory and antinociceptive activity of
Terminalia arjuna Roxb bark powder in mice and rats. Indian J Exp Biol 2009;47(7):577-83

19. Kameswara Rao B, Renuka Sudarshan P, Rajasekhar MD, Nagaraju N, Appa Rao CH. Antidiabetic activity of Terminalia pallida fruit in alloxan induced diabetic rats. J Ethnopharmacol 2003;85(1):169-72.

20. Jain SP, Verma DM, Singh SC, Singh JS, Kumar S. Flora of Haryana. Lucknow, India: Central Institute of Medicinal and Aromatic Plants; 2000 .

21. Khatri S, Phougat N, Chaudhary R, Singh B, Chhillar AK. Chemical composition, antioxidant, antibacterial and cytotoxicity analysis of Blumea lacera (Burm. f.) DC. Int J Pharm Pharm Sci 2016;8(8):313-9.

22. Nisar M, Tariq SA, Marwat IK, Shah MR, Khan IA. Antibacterial, antifungal, insecticidal, cytotoxicity and phytotoxicity studies on Indigofera gerardiana. J Enzyme Inhib Med Chem 2009;24(1):224-9.

23. Sharma B, Kumar P. Extraction and pharmacological evaluation of some extracts of Tridax procumbens and Capparis decidua. Int J Appl Res Nat Prod 2009;1(4):5-12.

24. Harborne JB. Phytochemical Methods. London: Chapman and Hall; 1991.

25. Paul S, Ghosh D, Ghosh AK, Bhowmick D, Bandyopadhyay D, Chattopadhyay A. Aqueous bark extract of Terminalia arjuna protects against phenylhydrazine induced oxidative damage in goat red blood cell membrane bound and metabolic enzymes. Int J Pharm Pharm Sci 2016;8(5):62-70

26. Javed T, Riaz S, Uzair M, Mustafa G, Mohyuddin A, Ahmad B. Biological activity of Terminalia arjuna on human pathogenic microorganisms. Pak J Pharm Res 2016;2(1):23-7.

27. Ramya S, Kalaivani $T$, Rajasekaran C, Jepachanderamohan $P$, Alaguchamy N, Kalayansundaram M, et al. Antimicrobial activity of aqueous extracts of bark, root, leaves and fruits of Terminalia arjuna wight and arn. Ethnobot Leafl 2008;12:1192-7.

28. Arya A, Nyamathulla S, Noordin MI, Ali M. Antioxidant and hypoglycemic activities of leaf extracts of three popular Terminalia species. E J Chem 2012;9(2):883-92.

29. Singh C, Saini NK, Manda H, Singhal M, Sachdeva K. Evaluation of antioxidant activity of Terminalia arjuna leaves extract. Pharmacol Online 2011;1:998-1006 